\title{
Plan de conservación para obras documentales y gráficas de Picasso
}

En diciembre de 2006, un equipo técnico del Centro de Intervención del IAPH se desplazaba al Museo Picasso de Málaga para evaluar el estado de conservación de unos importantes fondos bibliográficos. Desde entonces, una colección compuesta por 19 volúmenes con obra gráfica original de Picasso ha sido analizada por los técnicos del Taller de Patrimonio Documental y Gráfico del Centro de Intervención del IAPH, dando como resultado un detallado Informe de Asesoramiento Técnico, que recoge las actuaciones necesarias para frenar las alteraciones detectadas y preveer su correcta conservación futura.

\section{Los fondos mantienen \\ un buen estado de conservación general, aunque se han detectado alteraciones en algunas encuadernaciones}

Se trata de un conjunto de 19 volúmenes que tiene en común el contener obra gráfica original de Pablo Ruiz Picasso (1881-1973), de ahí la preocupación de la institución por su correcta conservación. La mayor parte de estos libros trata sobre las distintas facetas creativas de la obra de Picasso, pero también la integra algún volumen realizado por el propio artista.

De especial interés, por su singularidad y por su valor material, son los volúmenes correspondientes a dos catálogos de sus obras, que poseen una peculiar característica que los convierten en piezas excepcionales: a su indudable valor artístico, se suma la necesidad constante de su consulta en el centro por parte de estudiosos e investigadores. Este hecho ha condicionado que la intervención en los talleres del IAPH se realice en dos fases, para reducir al mínimo la retirada de la consulta de los fondos.

Todos los volúmenes están editados en el siglo XX, siendo el más antiguo el primer número de la obra de F. Mourlot -sobre la faceta de Picasso como litógrafo- (1919), y el más reciente de ellos se corresponde con el último volumen del catálogo de C. Zervos (1978). Estos volúmenes están almacenados en los depósitos de la biblioteca del
Museo, salvo los más consultados, ubicados en las vitrinas de la sala de consultas. Las óptimas condiciones de almacenamiento y depósito de estas obras ponen de manifiesto la preocupación del Museo por la óptima conservación del extraordinario patrimonio bibliográfico que atesora.

Los fondos mantienen un buen estado de conservación general, aunque se han detectado alteraciones en algunas encuadernaciones -derivadas de su uso y envejecimiento natural- que serán tratadas en base a un proyecto conservativo de mínima intervención que fortalezca los puntos débiles de dichas encuadernaciones, refuerce las estructuras internas, y mejore la protección frente al uso y manipulación de los volúmenes. Dicha intervención, que será llevada a cabo en la sede del IAPH en los próximos meses, supondrá la cristalización de uno de los proyectos de conservación del patrimonio bibliográfico andaluz más destacables en los últimos tiempos.

Eulalia Bellón

Centro de Intervención del IAPH 

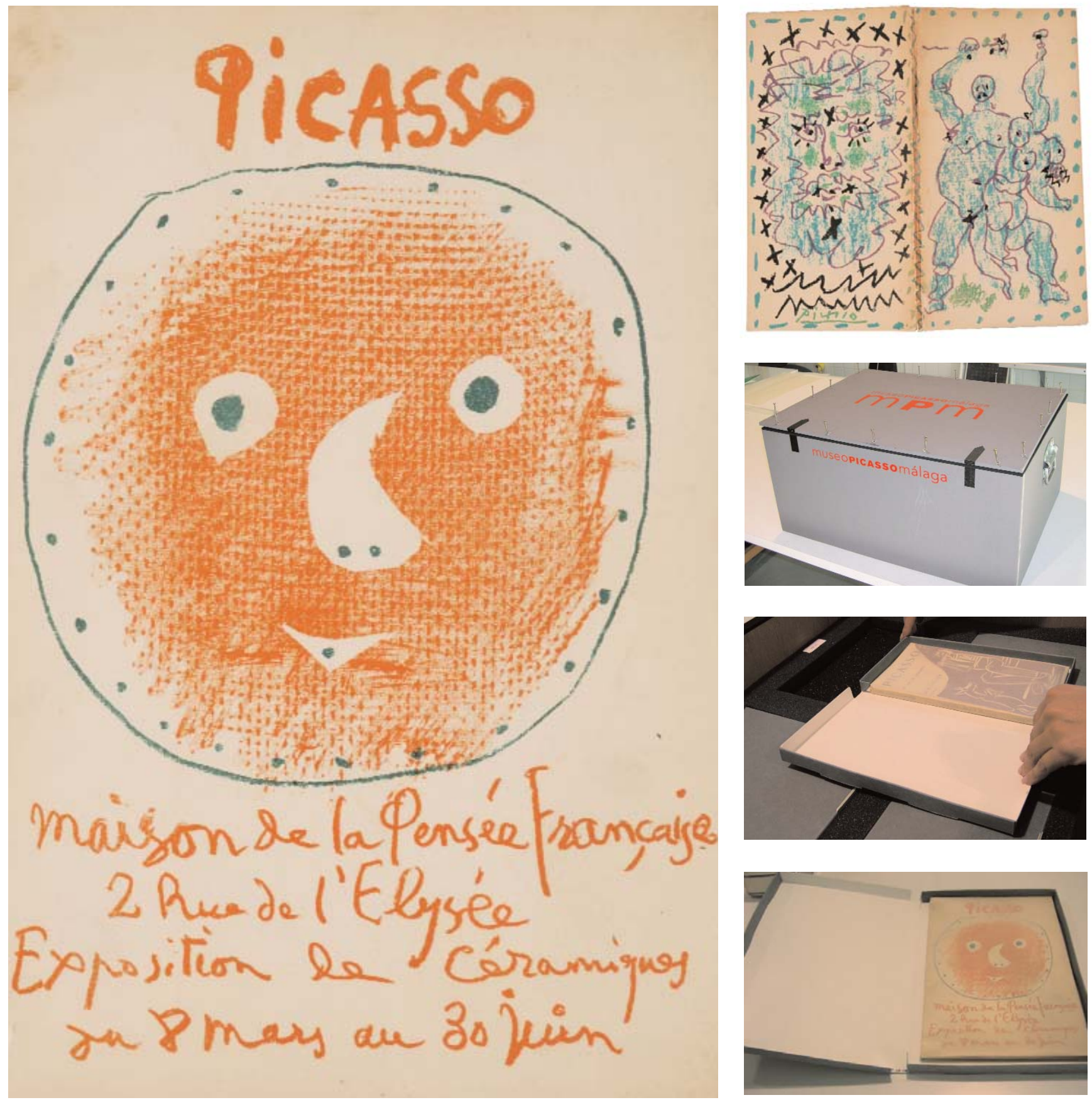